\title{
COMPORTAMENTO GEOELÉTRICO DA SEQUÊNCIA DRIFTE DA BACIA POTIGUAR (RN/CE)
}

\author{
João Paulo Lopes de Matos ${ }^{1,2}$, David Lopes de Castro ${ }^{3}$ e Nilo Costa Pedrosa Jr ${ }^{1,2}$ \\ Recebido em 23 dezembro, 2009 / Aceito em 1 julho, 2010 \\ Received on December 23, 2009 / Accepted on July 1, 2010
}

\begin{abstract}
A $70 \mathrm{~km}$ long geoelectric section, formed by twenty-nine vertical electric soundings (VES), reveals the geoelectrical configuration of the drift sequence of Potiguar basin, NE Brazil. This tectono-stratigraphic unit preserves structural records of tectonic activities after the end of the northeastern Brazilian rifting process, since the Albian to present day, and encompasses the main hydrocarbon reservoirs in the onshore portion of the basin. The VES were carried out every 2.0 or $3.0 \mathrm{~km}$ along a geophysical cross section to the major axis of the rift architecture. The VES were performed with maximum apertures of the current electrodes, which allow us to investigate depth of 500 to $1000 \mathrm{~m}$. The geological interpretative model was obtained by inversion of the soundings, constrained to a priori information derived from geological mapping, seismic reflection and well logging. The subsurface distribution of geoelectric resistivities reflects the strong structural conditioning of the drift sequence stratigraphic units. At the faulted border of the rift, a set of subvertical, normal faults causes a NW stepping increase in the thickness of the basin infill. While to southeast, the sedimentary cover of the marginal platform has a thickness relatively constant and is little affected by faulting. This model suggests that probable tectonic reactivation of brittle structures of the rift phase determines the structural setting of the drift tectono-sedimentary deposits in the onshore portion of Potiguar basin.
\end{abstract}

Keywords: geoelectric section, drift sequence, tectonic reactivation, Potiguar basin.

RESUMO. Uma seção geoelétrica de 70 km de extensão, constituída por vinte e nove sondagens elétricas verticais (SEV's), revela o comportamento geoelétrico da sequência drifte da Bacia Potiguar (RN/CE). Esta unidade tectono-estratigráfica preserva registros estruturais das atividades tectônicas posteriores ao encerramento do processo de rifteamento no Nordeste Setentrional, desde 0 Albiano até o Recente, e engloba os principais reservatórios de hidrocarbonetos da porção emersa da bacia. As SEV's foram executadas com separação de 2,0 ou 3,0 km, ao longo de um perfil geofísico transversal ao eixo principal da arquitetura rifte da bacia e com aberturas máximas dos eletrodos de corrente que permitiram investigar de 500 a $1000 \mathrm{~m}$ de profundidade. 0 modelo geológico interpretativo foi obtido pela inversão das sondagens elétricas, vinculado a informações a priori oriundas da geologia de superfície, de dados sísmicos de reflexão e da perfilagem de poços exploratórios. A distribuiç̧ão das resistividades das unidades geoelétricas em subsuperfície reflete o forte condicionamento estrutural dos níveis estratigráficos da sequência drifte. Na borda falhada do rifte, um conjunto de falhas normais subverticais provoca um aumento escalonado das espessuras do pacote sedimentar na direção noroeste. Já na plataforma marginal a sudeste do rifte, a cobertura sedimentar apresenta uma espessura relativamente constante e pouco afetada por expressivos falhamentos. Este modelo geotectônico sugere que prováveis reativações das estruturas rúpteis da fase rifte condicionam a estruturação dos depósitos tectono-sedimentares do período de deriva continental da porção emersa da Bacia Potiguar.

Palavras-chave: seção geoelétrica, sequência drifte, reativação tectônica, Bacia Potiguar.

\footnotetext{
1Programa de Pós-Graduação em Geologia, Universidade Federal do Ceará, Campus Universitário do PICl - Bloco 913, 60455-760 Fortaleza, Ceará, Brasil. Tel.: (85) 3366-9870; Fax: (85) 3366-9878-E-mails: jovempan@gmail.com; nilojuniorp@yahoo.com.br

${ }^{2}$ Laboratório de Geofísica de Prospecção e Sensoriamento Remoto (LGPSR), Departamento de Geologia, UFC.

${ }^{3}$ Departamento de Geologia, Universidade Federal do Rio Grande do Norte - E-mail: david@geologia.ufrn.br
} 


\section{INTRODUÇÃo}

Os métodos de eletrorresistividade, ou geoelétricos, foram desenvolvidos no início do século 20 e são, tradicionalmente, empregados em estudos hidrogeológicos e na perfilagem geofísica de poços de petróleo e água subterrânea (Reynolds, 1997; Telford et al., 1998). Tradicionalmente, a utilização da eletrorresistividade em estudos geotectônicos de bacias sedimentares é preterida em função da baixa resolução dos métodos elétricos na identificação de feições estruturais e estratigráficas e de dificuldades operacionais na aquisição dos dados de campo, como a necessidade de transportar e introduzir no solo grande número de eletrodos ligados por extensos cabos, principalmente em terrenos irregulares e cobertos por vegetação densa. Por sua vez, os métodos sísmicos, apesar dos altos custos operacionais, fornecem um imageamento detalhado da subsuperfície que os dados geoelétricos não conseguem oferecer. Além disso, métodos potenciais e eletromagnéticos permitem 0 estabelecimento de estações de medidas geofísicas de maneira mais rápida e simples e apresentam vantagens operacionais na investigação de alvos mais profundos.

Entretanto, os métodos geoelétricos podem ser empregados em estudos geotectônicos em áreas com baixo ou nenhum imageamento sísmico, com facilidades de acesso e relevo pouco acidentado ou também de forma integrada e/ou complementar a outros métodos geofísicos. Como exemplo, Singh et al. (2005) realizaram um estudo da estruturação geoelétrica no Vale do Puga (Índia), uma região próxima ao limite colisional das placas indiana e asiática. Unidades estratigráficas deformadas por falhas e fraturas foram reveladas por seções geoelétricas em contextos tectono-deposicionais tão diversos como a zona geotermal em Bakreswar, na porção da Índia (Majumdar et al., 2000), e pacotes de arenitos fraturados do Grupo Itararé na Bacia do Paraná (Campos et al., 2005). Appi \& Rostirolla (2004) fizeram uso de seções geoelétricas como método geofísico complementar ao levantamento de sísmica de reflexão para a modelagem de anisotropia em sistemas fraturados, também na Bacia do Paraná. Mais recentemente, Santos et al. (2006) desenvolveram um procedimento de inversão conjunta de dados gravimétricos e geoelétricos para 0 estudo hidrogeológico e estrutural na região do Sinai no nordeste do Egito. As medidas de eletrorresistividade forneceram detalhes sobre as camadas sedimentares para o modelo geofísico da subsuperfície que 0 método gravimétrico isoladamente não poderia alcançar. Pedrosa Jr (2010) aplicou o referido algoritmo de inversão conjunta em uma seção transversal ao rifte da Bacia Potiguar (RN/CE), revelando a complexa arquitetura interna do rifte na forma de um semi-gráben, preenchido por um pacote sedimentar de até $5.000 \mathrm{~m}$ de espessura.
Neste contexto, o presente artigo investiga o comportamento geoelétrico da sequência drifte ao longo de uma seção transversal ao Rifte Potiguar, no intuito de mapear possíveis reativações das principais falhas que definiram a geometria interna da bacia durante a fase rifte. 0 conhecimento do controle estrutural que estas falhas exerceram e ainda exercem sobre as unidades tectono-sedimentares das fases pós-rifte e drifte é estratégico para a prospecção de petróleo na bacia, uma vez que os principais reservatórios se encontram no pacote sedimentar superior e tais estruturas serviram não só como caminhos preferenciais para a migração dos hidrocarbonetos das rochas-fonte mais profundas, mas também forneceram as trapas estruturais preferenciais para o seu acúmulo.

\section{CONTEXTO GEOLÓGICO}

A Bacia Potiguar ocupa uma área de $48.000 \mathrm{~km}^{2}$, nos estados do Rio Grande do Norte e Ceará, sendo que 40\% deste total representam sua porção emersa e 0 restante sua porção submersa (Matos, 1992). A bacia é limitada a sul, leste e oeste por rochas do embasamento cristalino, a norte pelo Oceano Atlântico e a noroeste pela Bacia do Ceará (Fig. 1). Regionalmente, encontra-se situada quase totalmente no Domínio Rio Grande do Norte, segundo a subdivisão tectono-estratigráfica da porção setentrional da Província Borborema (Van Schmus et al., 1995; Fetter et al., 2003). 0 embasamento da Bacia Potiguar é representado pelos litotipos gnáissico-migmatíticos do Complexo Caicó, a faixa de rochas supracrustais do Grupo Seridó e as associações graníticas mais jovens.

A porção emersa da Bacia Potiguar é definida por um conjunto de grábens assimétricos, internamente separados por altos do embasamento e limitados por duas plataformas rasas, a leste (Plataforma de Touros) e a oeste (Plataforma de Aracati) do gráben principal, caracterizando um rifte intracontinental (Bertani et al., 1987). Os altos internos são representados por alongadas cristas do embasamento que separam os principais grábens. São interpretados como produto da formação dos grábens por meio de extensas falhas lístricas (Bertani et al., 1990; Matos, 1992). As plataformas de Touros e Aracati, que flanqueiam os grábens centrais, são afetadas pelo sistema de falhamentos presente nos mesmos. As plataformas apresentam um merguIho gradual, atingindo cerca de $1.500 \mathrm{~m}$ de profundidade junto às bordas dos grábens submersos.

A fase rifte da Bacia Potiguar iniciou em resposta ao rompimento das placas litosféricas entre a Província Borborema e 0 Escudo Nigeriano durante a abertura do Atlântico Sul, no Neocomiano Inferior (Françolin \& Szatmari, 1987; Matos, 1992). A sedimentação francamente continental em um sistema flúvio- 


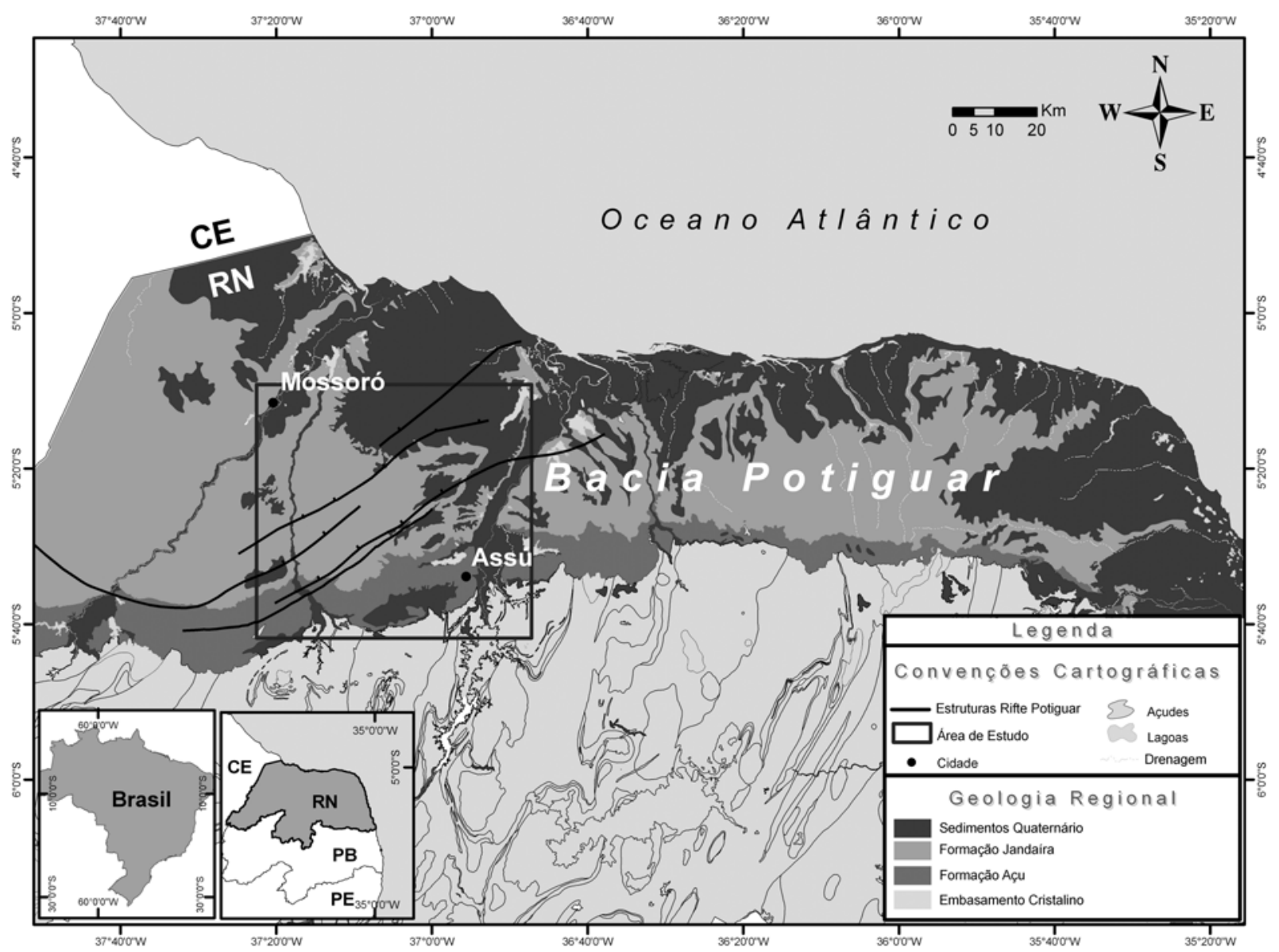

Figura 1 - Mapa geológico simplificado da Bacia Potiguar emersa, indicando a localização da área estudada.

deltaico-lacustre, que constitui a Formação Pendência (Souza, 1982), teve início ainda no Neocomiano, quando uma série de riftes foi estruturalmente controlada por falhamentos, dentre os quais, o mais importante é o Sistema de Falhas de Carnaúbais. Durante o Aptiano, com a continuidade do movimento de rotação horária do continente sul-americano, em relação ao africano, a Província Borborema foi submetida a uma distensão de direção N-S. Tal distensão paralisou as transcorrências dextrais NE-SW, bem como a sedimentação da porção emersa da Bacia Potiguar, prosseguindo apenas um rifteamento através de falhas $\mathrm{E}-\mathrm{W}$ e a deposição de sedimentos na porção submersa da referida Bacia.

0 período pós-rifte de subsidência térmica e generalizada é caracterizado pela deposição de uma sequência flúvio-deltaica durante 0 Aptiano e 0 Albiano, denominada Formação Alagamar (Araripe \& Feijó, 1994; Pessoa Neto et al., 2007). Por sua vez, as formações Açu, Ponta do Mel, Quebradas e Jandaíra, do Grupo Apodi, de idade albiana a campaniana, constituem a sequência drifte que se iniciou com rochas sedimentares conti- nentais clásticas, principalmente arenitos e pelitos, que gradaram para depósitos de plataforma rasa e carbonatos. A sequência drifte se encerra com a deposição dos folhelhos e carbonatos da Formação Jandaíra, que cobriram extensas áreas da Bacia Potiguar no Campaniano (Fig. 1).

De SE para NW ao longo do perfil geofísico, os litotipos aflorantes são representados, na base da coluna estratigráfica, por ortognaisses, xistos e granitos do embasamento da bacia, seguidos pelas sequências tectono-deposicionais clásticas e carbonáticas das formações Açu e Jandaíra, respectivamente (Fig. 2). Estas unidades encontram-se parcialmente recobertas pelas rochas sedimentares areno-argilosas terciárias da Formação Barreiras e por depósitos aluvionares e praiais recentes.

\section{LEVANTAMENTO GEOFÍSICO}

0 levantamento geoelétrico foi realizado ao longo de uma seção transversal de 70 km de extensão na porção centro-sul da Bacia Potiguar, entre as cidades de Mossoró e Assú no Rio Gran- 


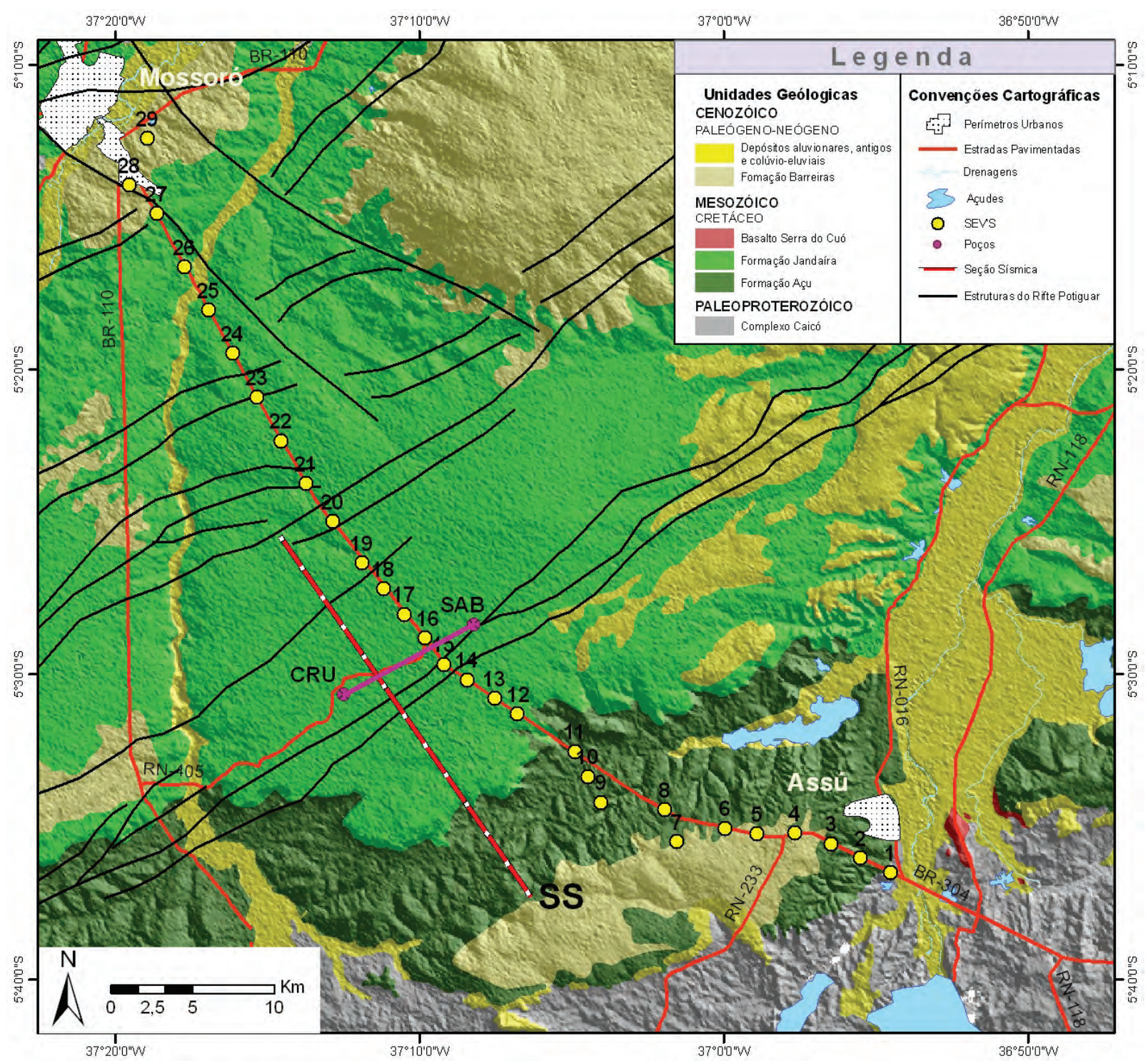

Figura 2 - Mapa geológico da Bacia Potiguar entre as cidades de Mossoró (RN) e Assú (RN), com a localização das sondagens elétricas verticais, dos poços estratigráficos SAB e CRU e da linha de reflexão sísmica (SS).

de do Norte (Fig. 2). Um conjunto de vinte e nove sondagens elétricas verticais (SEV's) foi executado nas margens da BR-304, espaçadas de 2,0 a 3,0 km. Os espaçamentos máximos entre os eletrodos de corrente (AB) foram de 2000 e $4000 \mathrm{~m}$, proporcionando profundidades de investigação teóricas de 500 e 1000 m, respectivamente.

As SEV's foram adquiridas com arranjo Schlumberger e espaçamento $A B / 2$ mínimo de 1,5 m e máximo de $1000 \mathrm{~m}$, no limite sul da bacia, ou $2000 \mathrm{~m}$, na zona de borda do Rifte Potiguar. Os eletrodos de corrente A e B utilizados são barras metálicas de aço, enquanto os eletrodos de potencial M e N são compostos de cobre. As profundidades de investigação teóricas são próximas ao espaçamento AB/4 (Telford et al., 1998). Deste modo, para que as linhas de corrente alcançassem profundidades maiores, fez-se necessário aumentar a distância AB, obedecendo a proporcionalidade de $M N \leq A B / 5$.

0 equipamento geofísico empregado na aquisição dos dados geoelétricos foi um o eletrorresistivímetro VT/VR - 250, fabricado pela Intergeo e composto por um transmissor AC/DC com potência máxima de $200 \mathrm{~W}$, um receptor AC com 10 dipolos de entrada e medidor digital de leitura em milivolts. Os dados de campo consistem dos valores de AB/2, MN/2, do fator geométrico 
$K(\mathrm{~m})$, da corrente $I(\mathrm{~mA})$, da diferença de potencial $\Delta V(\mathrm{mV})$ e da resistividade aparente $\rho a(\Omega . m)$. Os mesmos foram devidamente anotados em planilhas de campo. 0 fator geométrico consiste do arranjo espacial entre os eletrodos de corrente e potencial, dado pela expressão $[\pi \cdot(A M \cdot B N) / M N]$.

Durante a aquisição dos dados geoelétricos, as curvas de resistividade aparente foram plotadas em função das distâncias $A B / 2$, à medida que os valores eram obtidos, em gráficos bilogarítmicos, com o objetivo de manter um controle de qualidade das medidas. Por fim, os dados foram pré-processados, observando o seguinte procedimento: (a) descarte de pontos anômalos isolados; (b) suavização das curvas com correções de deslocamentos de ramos causados por efeitos laterais nos eletrodos de potencial; e (c) indicação de uma profundidade mínima para o embasamento cristalino nas SEV's que, em princípio, não alcançaram o mesmo. Nestas, 0 embasamento foi simulado pelo prolongamento da curva com uma inclinação de $45^{\circ}$ a partir do último ponto medido, como propôs Ward (1990).

\section{CURVAS GEOELÉTRICAS}

As curvas de resistividade aparente guardam estreita relação com a distribuição de resistividades e espessuras das unidades geoelétricas em subsuperfície. Para orientar a interpretação qualitativa de uma SEV, Telford et al. (1998) propõem uma classificação das curvas de campo com base nas variações relativas dos valores de resistividade aparente em função da abertura dos eletrodos de corrente $(A B / 2)$, para um modelo geoelétrico de três camadas (Tab. 1). A execução de sondagens verticais em locais de geologia conhecida possibilita reduzir a ambiguidade normalmente presente neste tipo de interpretação qualitativa, pela incorporação de informações a priori sobre as unidades geológicas e suas prováveis espessuras. Na presente pesquisa, os mapeamentos geológicos e estruturais de superfície disponíveis na vasta literatura da Bacia Potiguar, dados de perfilagem geofísica em dois poços exploratórios e uma seção sísmica de reflexão forneceram informações independentes aos modelos interpretativos dos dados geoelétricos.

Tabela 1 - Tipos de curvas de resistividade aparente padrões de 3 camadas (Telford et al., 1998).

\begin{tabular}{|c|c|c|}
\hline Resistividades & Tipo & Curva \\
\hline$\rho 1<\rho 2<\rho 3$ & A & Ascendente \\
\hline$\rho 1>\rho 2<\rho 3$ & H & De mínimo \\
\hline$\rho 1>\rho 2>\rho 3$ & Q & Descendente \\
\hline$\rho 1<\rho 2>\rho 3$ & K & De máximo \\
\hline
\end{tabular}

Para se classificar uma curva geoelétrica com mais de três camadas, toma-se 0 tipo padrão de curva que corresponde às três primeiras camadas, seguido do tipo padrão correspondente à segunda, terceira e quarta camadas e, assim, sucessivamente até finalizar a curva. Por exemplo, uma curva com cinco unidades geoelétricas e variações das resistividades do tipo $\rho 1>\rho 2<$ $\rho 3>\rho 4>\rho 5$ é classificada como uma curva HKQ.

Com base neste procedimento interpretativo, as 29 curvas de resistividade aparente foram classificadas nos seguintes tipos: A (3), H (14), HK (1), HA (9), QQ (1) e KA (1) (Tab. 2). Em função da geologia de superfície ao longo da seção transversal ao Rifte Potiguar, as SEV's foram reunidas em três grupos: I) SEV's que se localizam na região onde afloram as rochas da Formação Açu, que inclui 8 sondagens; II) SEV's localizadas na Formação Jandaíra, contendo 17 sondagens; e III) SEV's localizadas na Formação Barreiras, com 4 sondagens elétricas.

Tabela 2 - Classificação das curvas geoelétricas realizadas ao longo do rifte Potiguar. As SEV's dos grupos I (cinza claro), II (transparente) e III (cinza escuro) foram levantadas sobre as formações Açu, Jandaíra e Barreiras, respectivamente.

\begin{tabular}{|c|c|c|c|c|c|c|c|c|c|c|c|c|c|c|}
\hline Tipo & \multicolumn{14}{|c|}{ SEV } \\
\hline A & 01 & 19 & 20 & & & & & & & & & & & \\
\hline $\mathrm{H}$ & $\overline{02}$ & 07 & 08 & 09 & 11 & 04 & $\overline{05}$ & 06 & 24 & 25 & 26 & 27 & 28 & 29 \\
\hline HK & 03 & & & & & & & & & & & & & \\
\hline $\mathrm{HA}$ & 12 & 14 & 15 & 16 & 17 & 18 & 21 & 22 & 23 & & & & & \\
\hline QQ & 10 & & & & & & & & & & & & & \\
\hline $\mathrm{KA}$ & 13 & & & & & & & & & & & & & \\
\hline
\end{tabular}

As curvas geoelétricas do Grupo I são do tipo A, H, HK e QQ (Tab. 2). Todas terminam em um ramo ascendente, que na grande maioria tem inclinação próxima a $45^{\circ}$, indicando a presença de um embasamento infinitamente resistivo (Fig. 3). As SEV's deste grupo estão localizadas a SE do Rifte Potiguar, na Plataforma de Touros (Figs. 1 e 2). 0 contexto geológico local é constituído por um pacote sedimentar pouco espesso, composto pelas rochas siliciclásticas da Formação Açu, parcialmente recoberta por depósitos elúvio-coluvionares e aluvionares recentes. A profundidade de investigação de cerca de $500 \mathrm{~m}$ foi suficiente para atingir 0 embasamento cristalino da região em todas as SEV'S deste grupo. As sondagens que representam esse grupo são 1, 2, 3, 6 , $8,9,10$ e 11 .

No Grupo II, as curvas são dos tipos A, H, HA ou KA, sendo o tipo HA mais frequente (Fig. 3). Estas curvas mostram-se mais suave, provavelmente pelo fato do embasamento cristalino estar bem mais profundo. Todas elas apresentam como característica principal uma camada intermediária com baixa resistividade, re- 

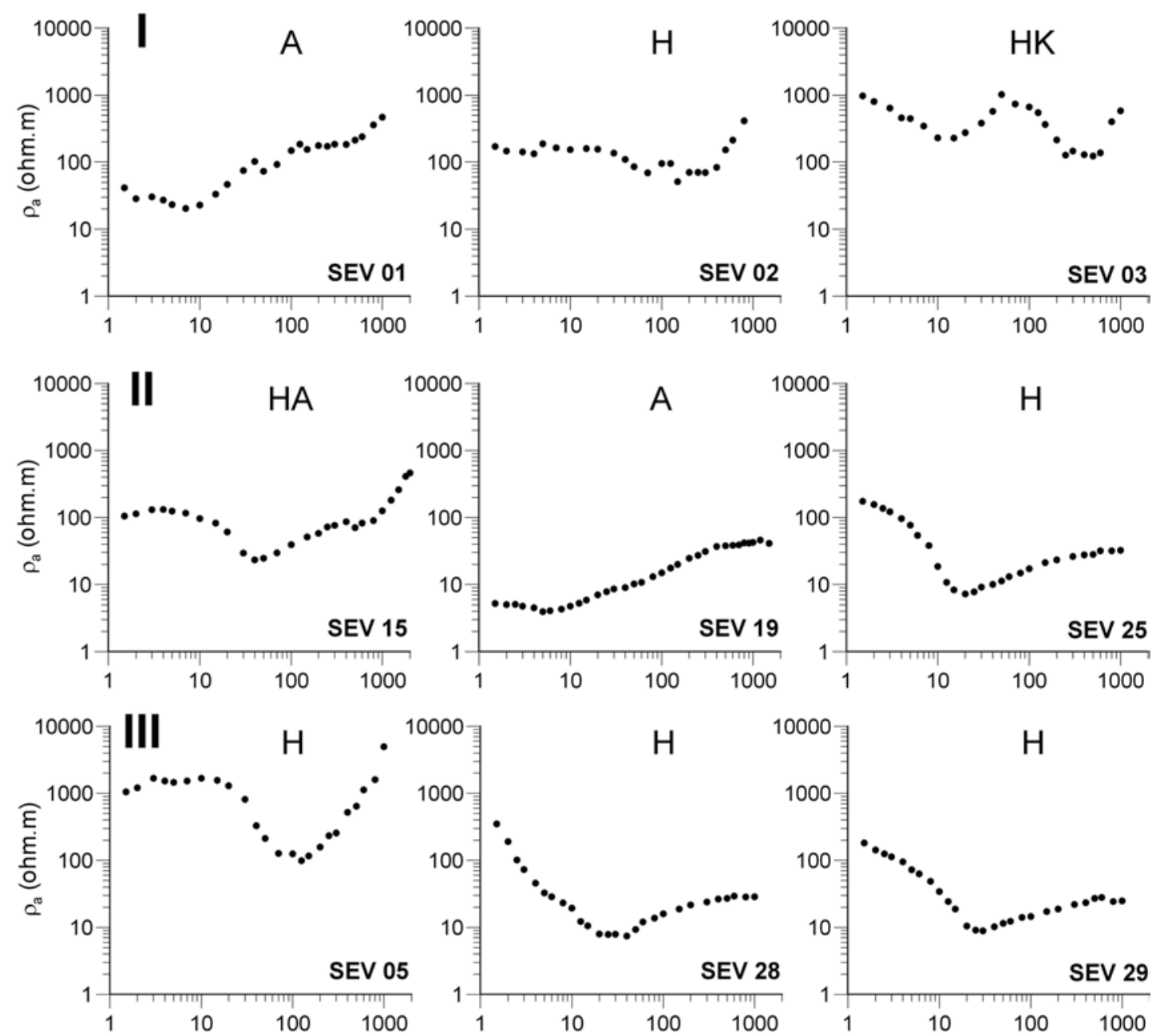

Figura 3 - Exemplos de curvas geoelétricas da Bacia Potiguar separadas em grupos (I, II, e III) em função da unidade geológica aflorante e do comportamento geoelétrico de subsuperfície. As letras A, H, HA e HK indicam os tipos de curvas de campo, que são descritos na Tabela 1.

presentada pelas rochas calcárias da Formação Jandaíra. Tal configuração geoelétrica imprime um caráter primordialmente do tipo $\mathrm{H}$ a curva de resistividade aparente. Este pacote carbonático, com grande extensão horizontal, serviu como horizonte-guia na elaboração do perfil geoelétrico. As SEV's 12 a 27 estão inseridas neste grupo.

No Grupo III, as curvas são do tipo H (Fig. 3), pouco suaves na porção SE do perfil geofísico, caracterizando uma camada inicial com maior resistividade. Todas elas apresentam como característica principal seu posicionamento em áreas onde afloram rochas sedimentares da Formação Barreiras (Fig. 2). Apesar deste pacote sedimentar mostrar-se pouco espesso, ele foi útil na correlação das SEV's, quando da confecção da seção geoelétrica. As SEV's desse grupo são as 4, 5, 28 e 29.
0 programa computacional VES for Windows 1.3, desenvolvido por Cooper (2000), foi utilizado para se obter estimativas das resistividades e espessuras das camadas geoelétricas para cada SEV. Este algoritmo emprega técnicas de Decomposição dos Valores Singulares e Ridge Regression para assegurar a estabilidade e convergência do processo de inversão 1-D para soluções plausíveis do ponto de vista da geologia local. Iterações usando este código foram realizadas automaticamente até que o modelo calculado satisfizesse uma diferença mínima entre os dados medidos e calculados. Quando necessário, ajustes nos modelos foram realizados de forma interativa para tornar os resultados mais consistentes com a realidade geológica conhecida. Para tanto, informações a priori sobre a geologia regional, propriedades físicas do material rochoso e geometria interna da bacia foram 

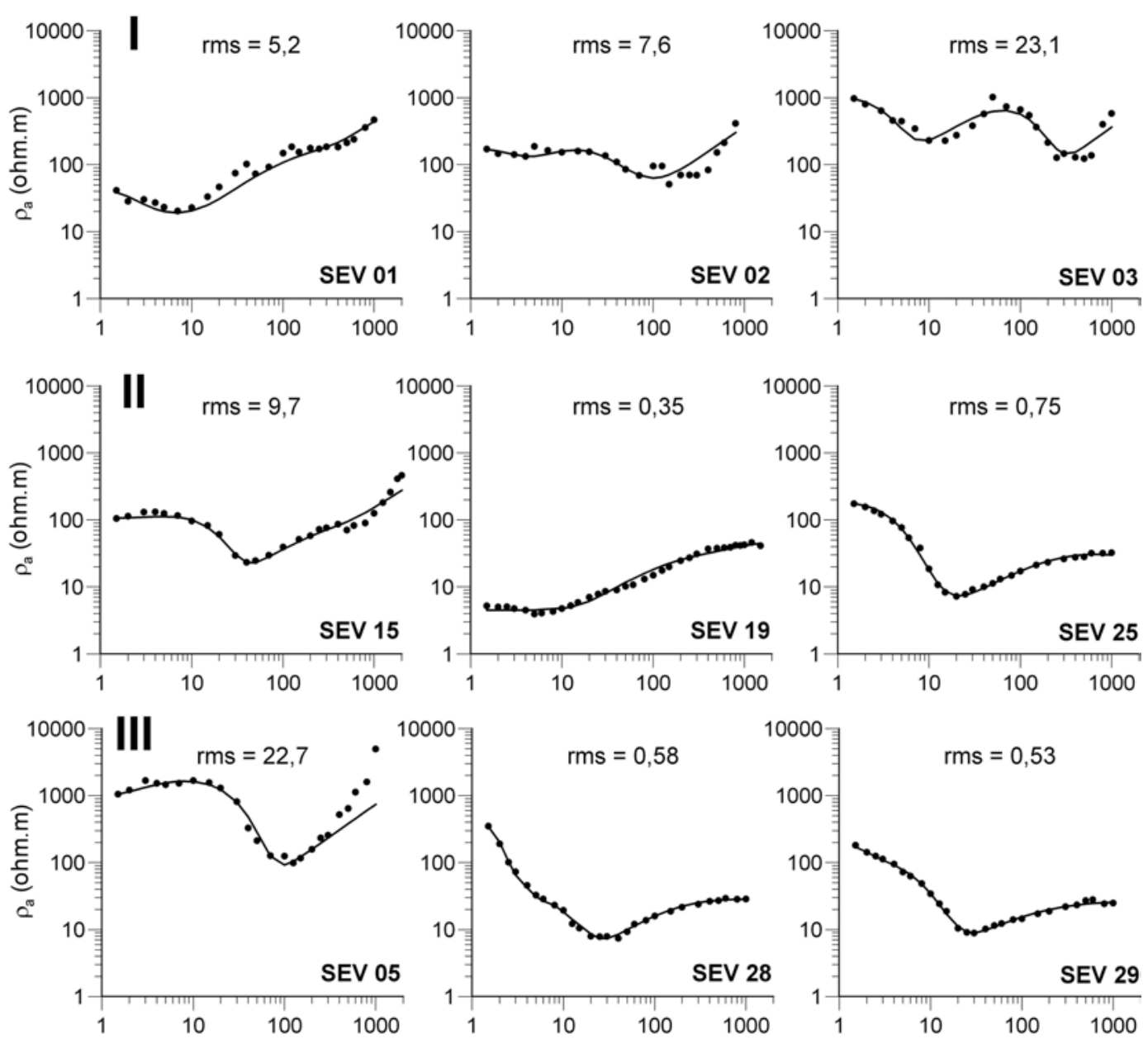

Figura 4 - Comparação das curvas geoelétricas observadas (pontos) e calculadas (linhas) a partir dos resultados da inversão 1-D. 0 grau de ajuste é expresso no sentido dos mínimos quadrados (rms).

consideradas a partir de dados de mapeamentos de superfície, perfilagem geofísica e sísmica de reflexão, respectivamente.

A Figura 4 mostra uma comparação das curvas geoelétricas observadas e calculadas, obtidas a partir da inversão 1-D das sondagens elétricas verticais. 0 grau de ajuste do modelo geofísico final foi estimado com base em critérios estatísticos no sentido dos mínimos quadrados. A Figura 5 apresenta os modelos finais, cujas camadas foram agrupadas em cinco unidades geoelétricas distintas, da base para o topo: a) embasamento cristalino; b) sequência rifte; c) Formação Açu; d) Formação Jandaíra; e e) cobertura sedimentar recente.

0 embasamento cristalino, aflorante na borda sul da Bacia Potiguar, é composto por rochas metamórficas diversas do Complexo Caicó de idade paleoproterozóica, intensamente intrudida por corpos granitóides brasilianos (Figs. 1 e 2). Esta unidade geológica revela-se bastante resistiva, variando de $1300 \mathrm{a}$
$75000 \Omega$.m (Fig. 6) na parte SE do perfil geofísico, onde as aberturas dos eletrodos de corrente $A B / 2$, de até 2000 m, permitiram sua investigação geoelétrica. Este amplo intervalo de resistividades certamente denota a complexidade litológica dos vários tipos rochosos que compõem esta unidade geológica. Tal complexidade na distribuição das resistividades desta unidade é refletida nos baixos índices de ajuste das curvas calculadas, da ordem de 23\% (Fig. 4). Nas sondagens elétricas que não atingem expressivas profundidades do embasamento (SEV's 13 a 29), 0 erro no ajuste das curvas calculadas, pelos critérios dos mínimos quadrados, é inferior a 10\% na porção SE do rifte e a 1\% no limite NW do perfil geofísico.

A unidade geoelétrica sobrejacente corresponde às rochas sedimentares da sequência rifte, cuja identificação no atual levantamento geoelétrico ficou aparentemente restrita às SEV's $16 \mathrm{e}$ 17. Suas resistividades são da ordem de $11000 \Omega$.m (Fig. 6), 

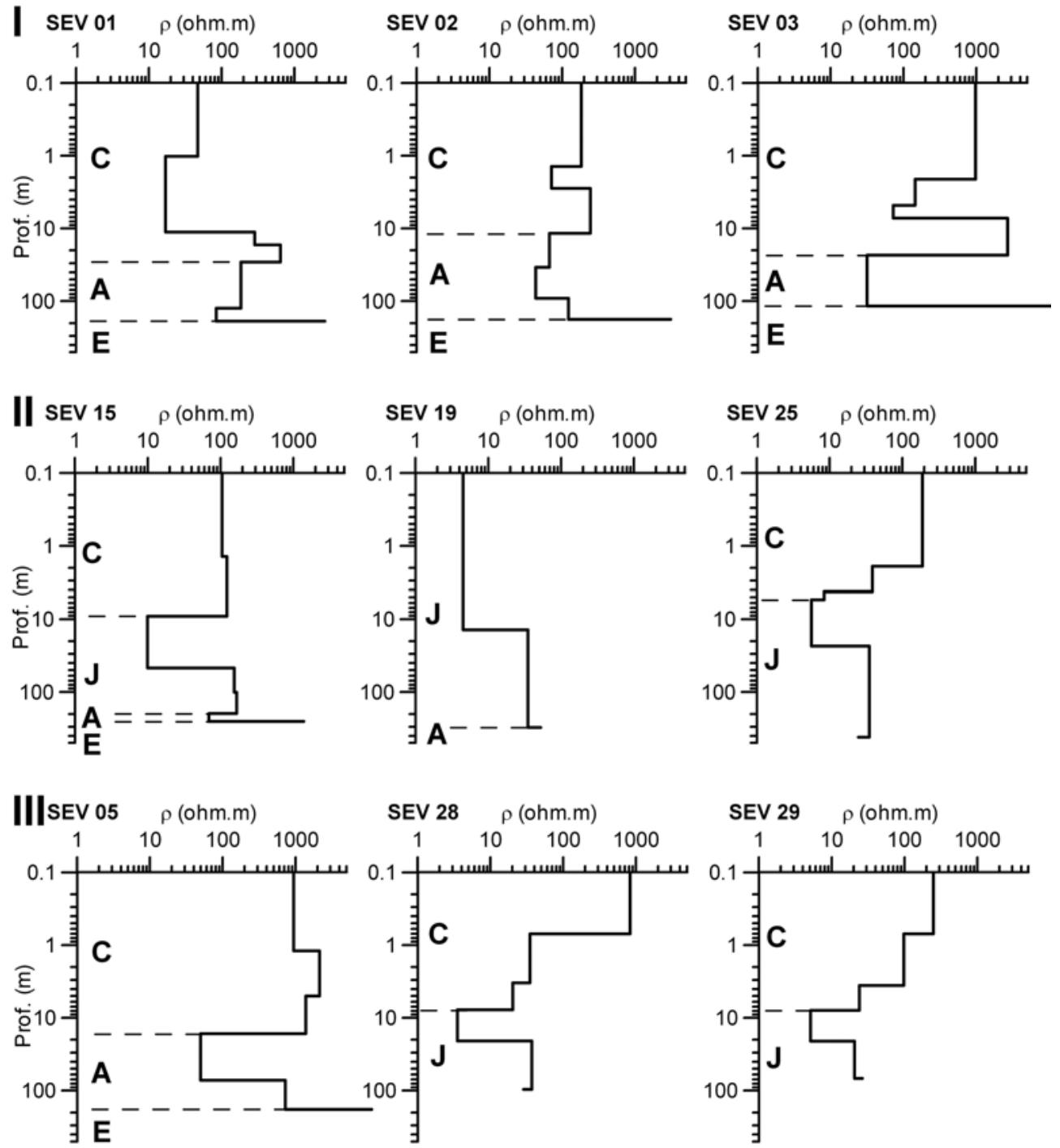

Figura 5 - Modelos geoelétricos obtidos pelo procedimento de inversão 1-D. C: cobertura sedimentar recente; J: rochas carbonáticas da Formação Jandaíra; A: rochas siliclásticas da Formação Açu; E: rochas ígneas e metamórficas do embasamento cristalino.

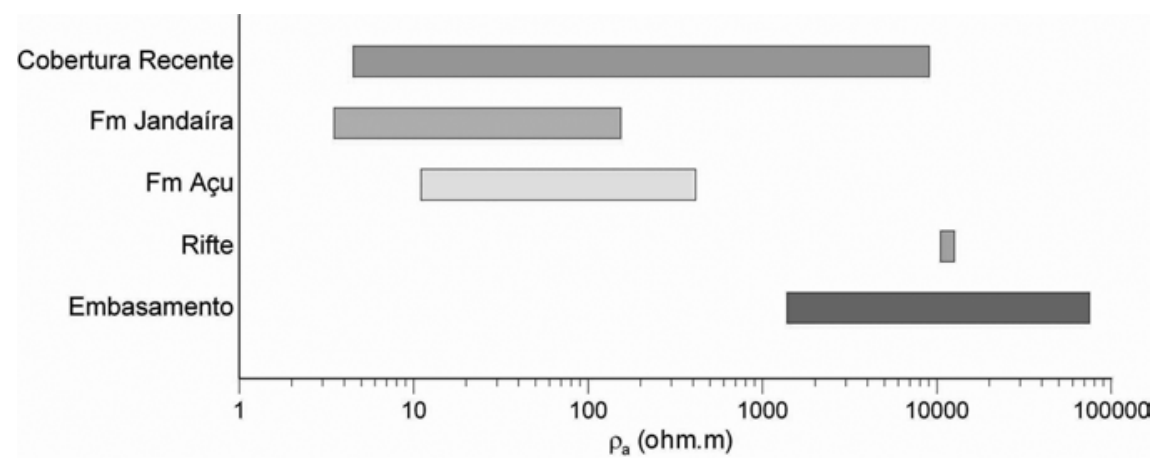

Figura 6 - Distribuição das resistividades das unidades geológicas da Bacia Potiguar emersa, obtidas pela inversão das 29 SEV's ao longo do perfil transversal ao rifte. 


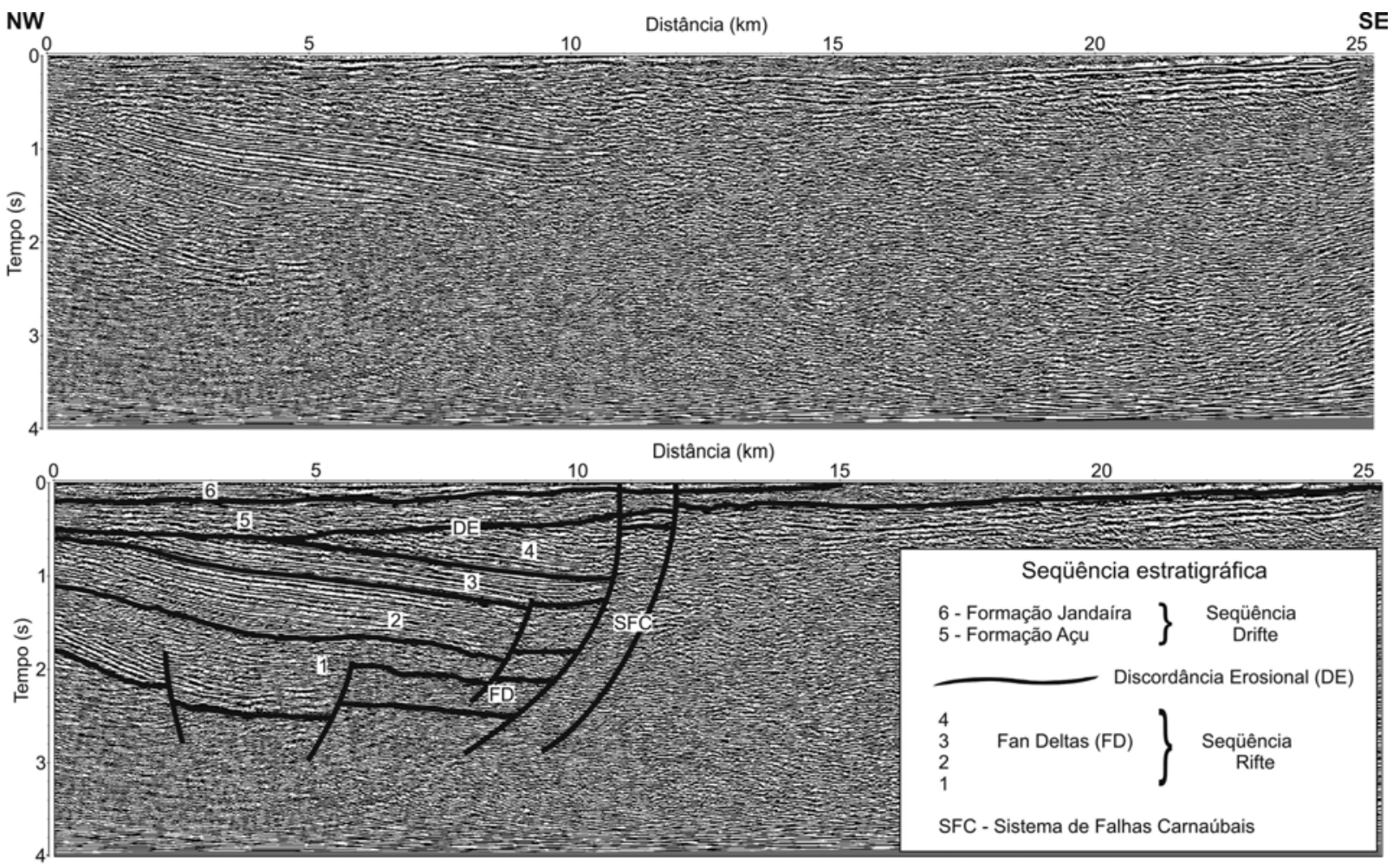

Figura 7 - Seção sísmica paralela ao perfil geoelétrico revelando a porção SE do semi-gráben típico do Rifte Potiguar e seu preenchimento tectono-estratigráfico.

refletindo seu alto conteúdo de material arenoso, como descrito por Araripe \& Feijó (1994). A diferenciação desta unidade geoelétrica é fortemente baseada na interpretação sismoestratigráfica de uma seção paralela ao perfil geofísico (Figs. 2 e 7). Deposições flúvio-deltaicas nas bordas falhadas do semi-grábens da Bacia Potiguar são bem documentados por Matos (1992) e Soares \& Rossetti (2005), com base em seções sísmicas e dados de poços de petróleo.

As duas unidades geoelétricas sobrejacentes são menos resistivas e estão presentes em quase todas as sondagens elétricas. A unidade mais inferior apresenta um intervalo de resistividades variando de 10 a $415 \Omega$.m (Figs. 5 e 6), relacionada às rochas siliciclásticas da Formação Açu, base da sequência drifte. Sobre esta, repousa a unidade geoelétrica com os menores valores de resistividade do pacote sedimentar local (3,5 a $154 \Omega$.m), representando a deposição francamente transgressiva de rochas carbonáticas da Formação Jandaíra. Castelo Branco et al. (2006) apresentam valores de resistividade para os calcários Jandaíra um pouco mais elevados, porém sua interpretação foi baseada em sondagens elétricas verticais distribuídas por uma área bem mais extensa da Bacia Potiguar, que certamente envolvem variações faciológicas mais abrangentes da deposição carbonática na região.
A unidade geoelétrica de topo é constituída pelo material inconsolidado e não saturado da cobertura sedimentar de idade tércio-quaternária. Esta unidade pouco espessa (Fig. 5), cujas resistividades variam em uma ampla faixa (4 a $9000 \Omega$ (m) (Fig. 6), reúne uma grande diversidade de litotipos, desde rochas areno-argilosas da Formação Barreiras até sedimentos elúviocoluvionares e aluvionares locais.

\section{MODELO GEOELÉTRICO}

Dados sísmicos, de perfilagem de poços e da geologia de superfície foram introduzidos para a confecção de uma seção geoelétrica transversal ao rifte da Bacia Potiguar e do modelo geológico interpretativo correspondente. Tais dados geofísicos foram adquiridos pela Petrobras e cedidos pela Agência Nacional do Petróleo, Gás Natural e Biocombustíveis (ANP) ao Laboratório de Geofísica de Prospecção Sensoriamento Remoto (LGPSR) da Universidade Federal do Ceará (UFC) para a execução deste e outros projetos de pesquisa na Bacia Potiguar.

A seção sísmica, paralela ao perfil geoelétrico (SS na Fig. 2), revela a porção sudeste da arquitetura típica de semi-grábens assimétricos do Rifte Potiguar (Fig. 7). A borda falhada do rifte ocorre entre as distâncias 10 a $12 \mathrm{~km}$ da seção sísmica, onde falhas normais subverticais do Sistema de Falhas de Carnaúbais 
(SFC) provocam rejeitos próximos a 5,0 km de profundidade. Junto às falhas principais de borda, ocorrem depósitos de fandelta interdigitados com quatro sequências sismoestratigráficas da deposição rifte da Bacia Potiguar. Estas sequências, pertencentes à Formação Pendências, foram definidas por Della Fávera et al. (1992) com base em critérios sismoestratigráficos e em dados litoestratigráficos e bioestratigráficos de poços e são delimitadas em seções sísmicas na extremidade sul do rifte, além de detalhadamente descritas por Soares \& Rossetti (2005). Seu topo é marcado por uma expressiva discordância erosional que a separa do pacote sedimentar da deposição drifte. Enquanto a espessura da sequência rifte diminui para NW, a cobertura mais recente torna-se mais espessa neste sentido devido às novas condições de subsidência térmica e deriva continental, vigentes durante o Albiano e Campaniano.

Os perfis geofísicos dos poços CRU e SAB, localizados próximos as SEV's 15 e 16 (Fig. 2), permitiram realizar uma correlação estratigráfica das unidades geoelétricas definidas pelas SEV's e os principais horizontes geofísicos discriminados em poços exploratórios da Bacia Potiguar (Fig. 8). Nestes poços, que se encontram próximos à borda SE do rifte e atingem quase $1000 \mathrm{~m}$ de profundidade, foram realizados os perfis de densidade (density log), resistividade (deep induction resistivity), gama natural (gamma ray) e potencial espontâneo (spontaneous potentia/). Uma análise qualitativa integrada dos diferentes perfis permite identificar seis horizontes geofísicos, que por sua vez são interpretados como sendo representativos das seguintes unidades geológicas: a) sequência rifte, na base; b) Formação Açu, dividida em quatros subunidades; e c) Formação Jandaíra, no topo.

Para a simplificação da interpretação das unidades geoelétricas desta pesquisa, é considerado que a unidade descrita como sequência rifte engloba tanto as rochas sedimentares da formação sin-rifte (Pendências) quanto da formação pós-rifte (Alagamar). Sendo assim, esta unidade geológica, observada somente nas SEV's 16 e 17, é marcada por um aumento nas densidades e resistividades dos perfis geofísicos dos poços CRU e SAB. Os valores de SP aumentam para o poço CRU e diminuem para o poço $S A B$, enquanto as contagens de radiação gama permanecem pouco alteradas (Fig. 8). Este conjunto de assinaturas geofísicas parece indicar a passagem de níveis mais arenosos e compactados da sequência rifte para níveis mais argilosos da base da Formação Açu. Além disso, 0 aumento marcante na resistividade da SEV 16, em torno de $320 \mathrm{~m}$ de profundidade, encontra correspondência nas expressivas variações de resistividade do poço $S A B$, a $480 \mathrm{~m}$ de profundidade, sugerindo tratar-se do mesmo contato geológico.

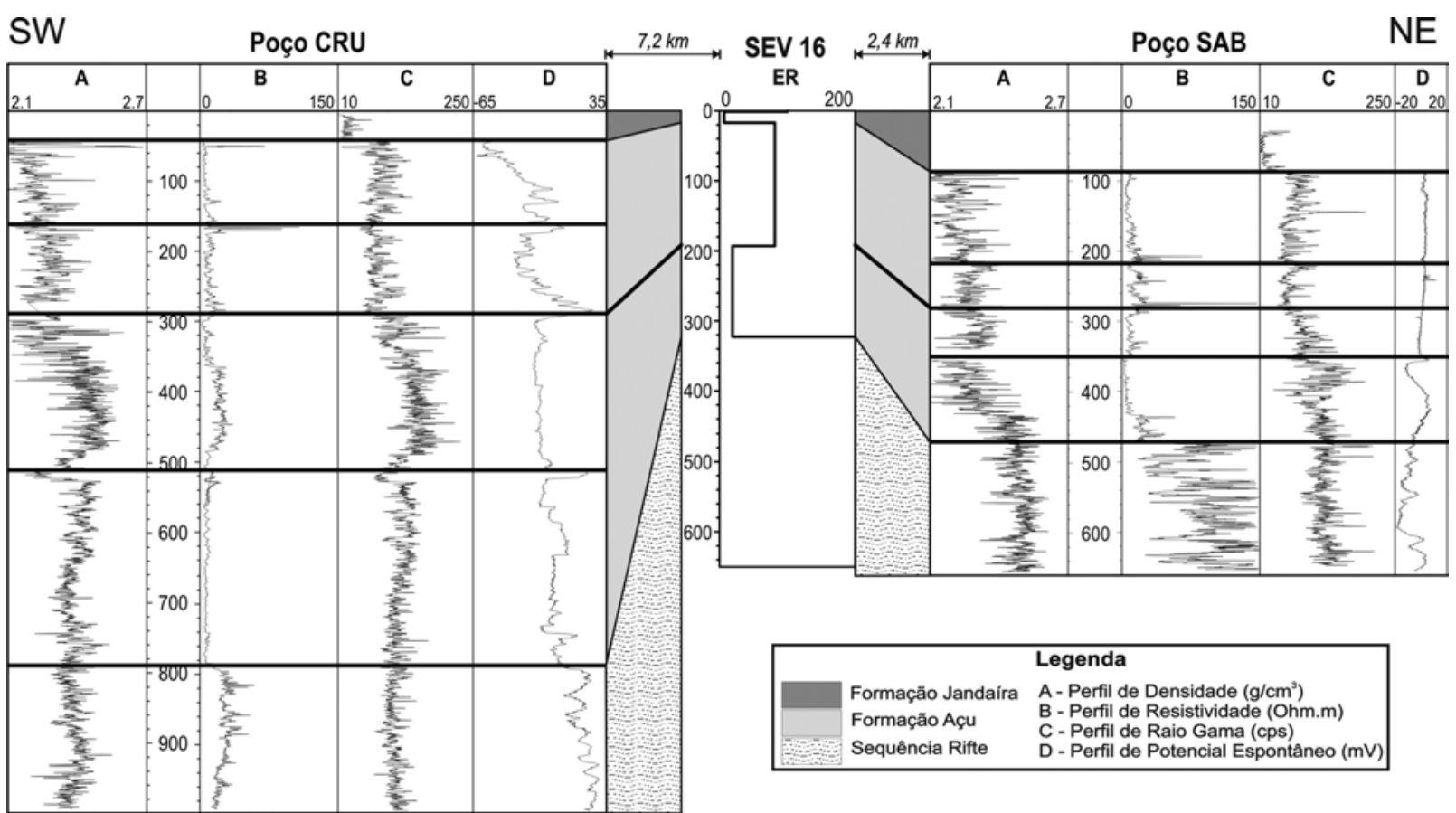

Figura 8 - Seção estratigráfica mostrando correlação entre os topos das principais unidades mapeadas por meio de perfis de poços e as unidades geoelétricas da SEV 16. 

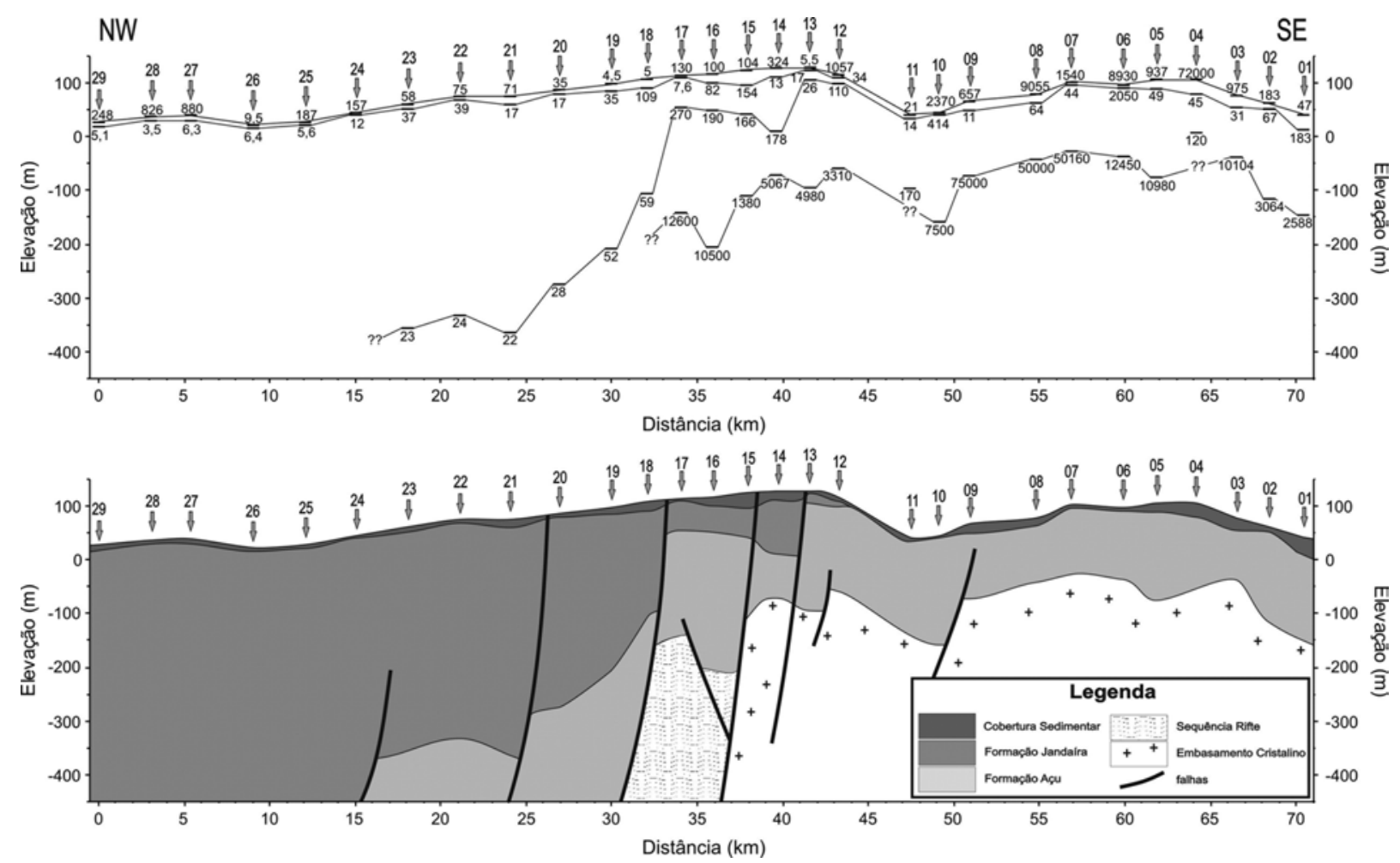

Figura 9 - Seção geoelétrica transversal ao rifte da Bacia Potiguar e seu respectivo modelo geológico interpretativo. As setas indicam a localização das SEV's e oS valores numéricos das resistividades das camadas.

De acordo com seu comportamento geofísico, o pacote sedimentar referente à Formação Açu pode ser dividido em quatro subunidades nos perfis de poços ou em duas unidades geoelétricas nas SEV's (Fig. 8). Estas subdivisões da Formação Açu são bem estabelecidas em perfis de poços exploratórios (Pessoa Neto et al., 2007; Santos, 2009) e refletem variações nos níveis de argilosidade e porosidade de uma sequência estratigráfica tipicamente siliciclástica. A passagem das duas subunidades inferiores para as duas superiores é marcada por uma diminuição da densidade e dos valores de raios gama e um aumento sutil da resistividade nos perfis dos poços CRU e SAB. Este contato ocorre a profundidades próximas a $300 \mathrm{~m}$. Na SEV 16, os dois horizontes que definem o comportamento elétrico da Formação Açu são diferenciados pela passagem da resistividade de 19,2 $\Omega$.m para $81,6 \Omega$.m, um pouco acima dos $200 \mathrm{~m}$ de profundidade.

Por fim, os carbonatos da Formação Jandaíra, no topo da coluna estratigráfica, são delimitados pela diminuição nos valores de raios gama em relação aos arenitos/argilitos subjacentes, entre as profundidades de $40 \mathrm{a} 80 \mathrm{~m}$ (Fig. 8). Os demais perfis não foram corridos neste intervalo, não revelando as assinaturas geofísicas desta unidade geológica. Na SEV 16, a sequência carbonática é marcada por um meio pouco resistivo (6,9 $\Omega$.m) e raso $(20 \mathrm{~m})$.

Uma seção geoelétrica transversal ao Rifte Potiguar foi então construída com a disposição geográfica dos resultados de todas as SEV's ao longo do perfil geofísico. Usando as informações da seção sísmica (Fig. 7) e dos perfis de poços (Fig. 8), é apresentado um modelo geológico interpretativo da seção geoelétrica da sequência drifte da Bacia Potiguar (Fig. 9). Neste modelo, podemos observar que a borda falhada do rifte é definida por um conjunto de falhas normais subverticais, com fortes mergulhos para NW e que devem pertencer ao Sistema de Falhas de Carnaúbais. Pelo menos, seis falhas principais e duas secundárias podem ser mapeadas em um intervalo de $35 \mathrm{~km}$ ao longo da região de borda do rifte.

A sudoeste do rifte, na região conhecida como Plataforma de Touros, o pacote sedimentar apresenta um espessura variável (120 a 200 m) e é preenchido essencialmente pelos depósitos siliciclásticos moderadamente resistivos da Formação Açu e da cobertura sedimentar tércio-quaternária. Já na região do rifte (até a distância de 40 km no perfil geoelétrico da Fig. 9), observa-se na base do pacote sedimentar e junto à falha principal uma unidade 
geoelétrica bastante resistiva, interpretada como rochas sedimentares da sequência rifte. Seus limites laterais são marcados pelas falhas normais e sua base sobre 0 embasamento cristalino deve ocorrer abaixo da profundidade de investigação de cerca de 500 a $1000 \mathrm{~m}$ das sondagens elétricas verticais executadas neste local.

A sequência drifte sobrejacente é constituída na base pelas rochas siliciclásticas da Formação Açu e no topo pela sequência carbonática pouco resistiva da Formação Jandaíra (Fig. 9). As profundidades do topo da Formação Açu aumentam rapidamente na direção NW, governadas pelas falhas normais, enquanto que as resistividades apresentam uma tendência de diminuir com a profundidade, chegando a valores mínimos de $22 \Omega$.m. Do mesmo modo, enquanto o pacote carbonático da Formação Jandaíra aumenta expressivamente sua espessura em direção ao centro do rifte, suas resistividades diminuem no intervalo de 3,5 a 5,1 $\Omega$.m. As descontinuidades laterais observadas nos contatos destas unidades geológicas, através do seu comportamento geoelétrico, sugerem que importantes reativações das estruturas rúpteis do rifte afetaram sobremaneira as sequências estratigráficas depositadas após 0 encerramento da fase de rifteamento da bacia. Esta região do Nordeste do Brasil apresenta um histórico de reativações dos principais trends estruturais, que se reflete ao longo do tempo geológico até as atividades sismológicas atuais (Bezerra \& VitaFinzi, 2000; Bezerra et al., 2007).

Por fim, as resistividades da cobertura sedimentar recente apresentam-se bem inferiores na região do rifte em relação à porção sudeste do perfil (Fig. 9). Tal fato, provavelmente, reflete 0 solo raso e argiloso, produto do intemperismo das rochas calcárias desta região, contrastante aos sedimentos arenosos grossos e cascalhosos bastante resistivos, que ocorrem na borda sul da Bacia Potiguar. No limite NW do perfil, valores de resistividade da ordem de $800 \Omega$.m parecem estar relacionados aos depósitos terciários da Formação Barreiras, aflorantes na região.

\section{CONCLUSÕES}

0 comportamento geoelétrico da porção drifte da Bacia Potiguar (NE do Brasil) foi obtido através de um perfil geofísico transversal ao eixo principal da estrutura rifte, que constou de vinte e nove sondagens elétricas verticais com aberturas máximas de $A B / 2$ de até $2000 \mathrm{~m}$ e espaçadas de 2,0 a 3,0 km. Para uma profundidade de investigação em torno de $500 \mathrm{~m}$, foi possível pesquisar, além de uma espessa parte da sequência drifte, o topo da sequência rifte na borda falhada do rifte e 0 embasamento cristalino subjacente na região da plataforma marginal.

Informações a priori advindas da geologia de superfície, seção sísmica e perfilagem geofísica de poços exploratórios foram consideradas para a confecção de uma seção geoelétrica e do modelo geológico interpretativo decorrente. Como resultado, cinco unidades litoestratigráficas puderam ser individualizadas na porção do rifte e três na região da plataforma marginal. A coluna geológica completa é constituída na base pelo embasamento gnaíssico-migmatítico e granítico proterozoíco extremamente resistivo do Complexo Caicó, recoberto pelas rochas sedimentares da bacia. Na base do pacote sedimentar, encontram-se as rochas areno-argilosas da sequência rifte do Neocomiano Inferior, com altos valores de resistividade, cuja ocorrência na seção geoelétrica está restrita ao limite SE do rifte. A sequência drifte sobrejacente é divida pelo pacote de rochas siliciclásticas pouco resistivas da Formação Açu, que ocorre ao longo de todo o perfil geofísico, e a sequência carbonática condutiva da Formação Jandaíra. Esta última ocorre apenas na porção do Rifte Potiguar. Por fim, o topo da seção geoelétrica é composto pela cobertura sedimentar recente pouco espessa mais contínua, normalmente mais resistiva.

0 comportamento geoelétrico da sequência drifte revela que a borda falhada do Rifte Potiguar é marcadamente condicionada por falhas normais subverticais com forte mergulho para NW. Ao longo de uma faixa de $35 \mathrm{~km}$, observa-se um conjunto de oito faIhas normais, pertencentes ao Sistema de Falhas de Carnaúbais, que provoca escalonamento das camadas sedimentares, com aumento acentuado de suas espessuras para NW. Esta configuração estrutural sugere que importantes reativações das falhas geradoras do rifte afetaram sobremaneira as sequências tectonoestratigráficas do período de deriva continental da região emersa da Bacia Potiguar. Tais reativações parecem ser um dos mecanismos principais de migração dos hidrocarbonetos gerados nas rochas-fonte da sequência rifte para as rochas-reservatório das formações superiores da fase drifte.

\section{AGRADECIMENTOS}

Esta pesquisa recebeu suporte financeiro do Conselho Nacional de Desenvolvimento Científico e Tecnológico (CNPq) (Projeto 474062/2006-6). Os autores agradecem à Agência Nacional do Petróleo, Gás Natural e Biocombustíveis (ANP) pela cessão dos dados sísmicos e perfis geofísicos de poços. JPL Matos e NC Pedrosa Jr. foram bolsistas de Iniciação Científica do CNPq e atualmente recebem bolsa de mestrado da Coordenação de Aperfeiçoamento de Pessoal de Nível Superior (CAPES). DL de Castro é bolsista de Produtividade em Pesquisa do CNPq.

\section{REFERÊNCIAS}

APPI CJ \& ROSTIROLLA SP. 2004. Modelagem da anisotropia em sistemas fraturados a partir de estudos de alta resolução na Bacia do Paraná, Brasil. Boletim de Geociências da Petrobras, 12(1): 125-147. 
ARARIPE PT \& FEIJÓ FJ. 1994. Bacia Potiguar. Boletim de Geociências da Petrobras, 8(1): 127-141.

BERTANI RT, APOLUCENO NETO AF \& MATOS RMD. 1987. 0 habitat do petróleo e as perspectivas exploratórias da Bacia Potiguar emersa. Boletim de Geociências da Petrobras, 1(1): 41-49.

BERTANI RT, COSTA IG \& MATOS RMD. 1990. Evolução tectonosedimentar, estilo estrutural e habitat do petróleo na Bacia Potiguar. In: GABAGLIA GPR \& MILANI EJ (Eds.). Origem e Evolução das Bacias Sedimentares. Petrobras, Rio de Janeiro, 291-310.

BEZERRA FHR \& VITA-FINZI C. 2000. How active is a passive margin? Paleoseismicity in northeastern Brazil. Geology, 28: 591-594.

BEZERRA FHR, TAKEYA MK, SOUSA MOL \& DO NASCIMENTO AF. 2007. Coseismic reactivation of the Samambaia fault. Tectonophysics, 430: 27-39.

CAMPOS AF, RIGOTI A, ROSTIROLLA SP, APPI CJ, KRAFT RP \& BARTOSZECK MK. 2005. Utilização da eletrorresistividade na caracterização de arenitos fraturados do grupo Itararé - Bacia do Paraná. Boletim Paranaense de Geociências, 56: 89-103.

CASTELO BRANCO RMG, SOUZA ML, PINÉO TRG \& DE CASTRO DL. 2006. Comportamento das bacias sedimentares da região semi-árida do Nordeste Brasileiro porção sul da Bacia Potiguar. Levantamentos geofísicos na porção sul da Bacia Potiguar. Relatório conclusivo, vol. 02 - Eletrorresistividade, Serviço Geológico do Brasil (CPRM), Rio de Janeiro, $78 \mathrm{p}$.

COOPER GRJ. 2000. Modelling and inversion of Schlumberger resistivity soundings. Department of Geophysics and Geology, University of Witwatersrand, South Africa. Disponível em:

$<$ http://www.wits.ac.za/science/geophysics/gc.htm>. Acesso em: 10 mar. 2009.

DELLA FÁVERA JC, ROSSETTI EL, GUZZO JVP, MATSUDA NS, SOARES UM, HASHIMOTO AT, ALVES DB, CASTRO JC, AZAMBUJA NC \& RODRIGUES R. 1992. Estratigrafia de sequências da Formação Pendência, Bacia Potiguar. PETROBRAS, DEPEX, Rio de Janeiro, Relatório Interno, 2.

FETTER AH, DOS SANTOS TJS, VAN SCHMUS WR, HACKSPACHER PC, BRITO NEVES BB, ARTHAUD MH, NOGUEIRA NETO JA \& WERNICK E. 2003. Evidence for Neoproterozoic continental arc magmatism in the Santa Quitéria batholith of Ceará State, NW Borborema Province, NE Brazil: implications for the assembly of West Gondwana. Gondwana Research, 6: 265-273.

FRANÇOLIN JBL \& SZATMARI P. 1987. Mecanismo de rifteamento da porção oriental da margem norte brasileira. Revista Brasileira de Geociências, 17: 196-207.
MAJUMDAR RK, MAJUMDAR N \& MUKHERJEE AL. 2000. Geoelectric investigations in Bakreswar geothermal area, West Bengal, India. Journal of Applied Geophysics, 45: 187-202.

MATOS RMD. 1992. The northeast Brazilian rifts system. Tectonics, 11: 766-791.

PEDROSA Jr NC. 2010. Inversão Conjunta (Gravimetria e Resistividade) e Modelagem Sísmica na Porção Pós-Rifte da Bacia Potiguar RN/CE: Investigação de Estruturas Acumuladoras de Petróleo e Água Subterrânea. Dissertação de Mestrado, UFC, 121 p.

PESSOA NETO OC, SOARES UM, SILVA JGF, ROESNER EH, FLORÊNCIO CP \& SOUZA CAV. 2007. Bacia Potiguar. Boletim de Geociências da Petrobras, 15(2): 357-369.

REYNOLDS JM. 1997. An Introduction to Applied and Environmental Geophysics. John Wiley \& Sons, $796 p$.

SANTOS SCN. 2009. Análise estratigráfica e caracterização faciológica de depósitos neocretácicos pertencentes à Formação Açu, Bacia Potiguar emersa - RN. Dissertação de Mestrado, UFRGS, 60 p.

SANTOS FAM, SULTAN SA, REPRESAS P \& EL SORADY AL. 2006. Joint inversion of gravity and geoelectrical data for groundwater and structural investigation: application to the northwestern part of Sinai, Egypt. Geophysical Journal International, 165: 705-718.

SINGH UK, TIWARI RK \& SINGH SB. 2005. One-dimensional inversion of geo-electrical resistivity sounding data using artificial neural networks - a case study. Computers \& Geosciences, 31: 99-108.

SOARES UM \& ROSSETTI EL. 2005. Tectonismo e sedimentação na porção SW do Rifte Potiguar - Bacia Potiguar emersa. Boletim de Geociências da Petrobras, 13(2): 149-166.

SOUZA SM. 1982. Atualização da litoestratigrafia da Bacia Potiguar. In: Congresso Brasileiro de Geologia, 32., 1982. Salvador. Anais... São Paulo: Sociedade Brasileira de Geologia, 5: 2392-2406.

TELFORD WM, GELDART, LP, SHERIFF RE \& KEYS DA. 1998. Applied Geophysics. 2 ed., Cambridge University Press, 860 p.

VAN SCHMUS WR, BRITO NEVES BB, HACKSPACHER PC \& BABINSKY M. 1995. U/Pb and Sm/Nd geochronologic studies of the eastern Borborema Province, Northeastern Brazil: initial conclusions. Journal of South American Earth Science, 8: 267-288.

WARD SH. 1990. Resistivity and Induced Polarization Methods. In: WARD SH (Ed.). Geotechnical and Environmental Geophysics. Vol. 1, SEG, 147-189. 


\section{NOTAS SOBRE OS AUTORES}

João Paulo Lopes de Matos é geólogo pela UFC (2009) e cursa o Programa de Pós-Graduação em Geologia da UFC. Atua na área de Geociências, com ênfase em Geofísica Aplicada ao estudo de bacias sedimentares e cartografia geofísica regional. É membro da Sociedade Brasileira de Geofísica.

David Lopes de Castro é geólogo pela UFRN, mestre em Geofísica pela UFPA e concluiu o doutorado em Geofísica na Christian-Albrechts Universität - Kiel (Alemanha) em 1995. É professor associado da Universidade Federal do Rio Grande do Norte. Atua na área de Geociências, com ênfase em Geofísica Aplicada ao estudo de bacias sedimentares, cartografia geofísica regional, hidrogeologia e meio ambiente. É membro da Sociedade Brasileira de Geofísica e da Sociedade Brasileira de Geologia.

Nilo Costa Pedrosa Júnior é geólogo e concluiu o mestrado em Geologia, na área de Geodinâmica e Recursos Minerais pela UFC em 2010. Atua na área de Geociências, com ênfase em Geofísica Aplicada ao estudo de bacias sedimentares e cartografia geofísica regional. É membro da Sociedade Brasileira de Geofísica. 